Bond University

Research Repository

\title{
( \\ Boovo \\ UNIVERSITY
}

The Mediterranean diet and menopausal health: an EMAS position statement

Cano, Antonio; Marshall, Skye; Zolfaroli, Irene; Bitzer, Johannes ; Ceausu, Iuliana; Chedraui, Peter ; Durmusoglu, Faith; Erkkola, Risto; Goulis, Dimitrios G; Linden Hirschberg, Angelica; Kiesel, Ludwig; Lopes, Patrice; Pines, Amos; van Trotsenburg, Mick; Lambrinoudaki, Irene; Rees, Margaret

Published in:

Maturitas

DOI:

10.1016/j.maturitas.2020.07.001

Licence:

CC BY-NC-ND

Link to output in Bond University research repository.

Recommended citation(APA):

Cano, A., Marshall, S., Zolfaroli, I., Bitzer, J., Ceausu, I., Chedraui, P., Durmusoglu, F., Erkkola, R., Goulis, D. G., Linden Hirschberg, A., Kiesel, L., Lopes, P., Pines, A., van Trotsenburg, M., Lambrinoudaki, I., \& Rees, M. (2020). The Mediterranean diet and menopausal health: an EMAS position statement. Maturitas, 139, 90-97. https://doi.org/10.1016/j.maturitas.2020.07.001

\section{General rights}

Copyright and moral rights for the publications made accessible in the public portal are retained by the authors and/or other copyright owners and it is a condition of accessing publications that users recognise and abide by the legal requirements associated with these rights.

For more information, or if you believe that this document breaches copyright, please contact the Bond University research repository coordinator. 
Highlights

- Globally, 985 million women are aged 50 and over, leading to increasing concerns about chronic diseases which can adversely affect quality of life and independent living.

- Optimization of diet is increasingly being accepted as playing a role in the strategies to reduce the risk of chronic disease and to promote menopausal health.

- Overall, both all-cause and cause-specific mortality are reduced by the Mediterranean diet, with the major benefits seen with cardiovascular disease.

- $\quad$ Short-term adherence to the Mediterranean diet may improve vasomotor symptoms.

The Mediterranean diet and menopausal health: an EMAS position statement

Antonio Cano ${ }^{1}$, Skye Marshall 2, Irene Zolfaroli ${ }^{1}$, Johannes Bitzer ${ }^{3}$, Iuliana Ceausu ${ }^{4}$, Peter Chedraui ${ }^{5}$, Fatih Durmusoglu ${ }^{6}$, Risto Erkkola ${ }^{7}$, Dimitrios G. Goulis ${ }^{8}$, Angelica Lindén Hirschberg ${ }^{9}$, Ludwig Kiesel ${ }^{10}$, Patrice Lopes ${ }^{11}$, Amos Pines ${ }^{12}$, Mick van Trotsenburg ${ }^{13}$, Irene Lambrinoudaki ${ }^{14}$, Margaret Rees 15

1. Department of Pediatrics, Obstetrics and Gynecology, University of Valencia and INCLIVA, Valencia, Spain

2. Nutrition Research Australia, New South Wales, Australia; and Bond University Nutrition \& Dietetics Research Group, Faculty of Health Sciences and Medicine, Bond University, Queensland, Australia.

3. Department of Obstetrics and Gynecology, University Hospital, Basel, Switzerland

4. Department of Obstetrics and Gynecology I, "Dr. I. Cantacuzino" Hospital, "Carol Davila" University of Medicine and Pharmacy, Bucharest, Romania

5. Instituto de Investigación e Innovación de Salud Integral (ISAIN), Facultad de Ciencias Médicas, Universidad Católica de Santiago de Guayaquil, Guayaquil, Ecuador

6. Istanbul Medipol International School of Medicine, Istanbul, Turkey

7. Department of Obstetrics and Gynecology, University Central Hospital Turku, Finland

8. Unit of Reproductive Endocrinology, 1st Department of Obstetrics and Gynecology, Medical School, Aristotle University of Thessaloniki, Greece.

9. Department of Women's and Children's Health, Karolinska Institutet and Department of Gynecology and Reproductive Medicine, Karolinska University Hospital, Stockholm, Sweden

10. Department of Gynecology and Obstetrics, University of Münster, Münster, Germany

11. Nantes, France Polyclinique de l'Atlantique Saint Herblain. F 44819 St Herblain France, Université de Nantes F 44093 Nantes Cedex, France

12. Sackler Faculty of Medicine, Tel-Aviv University, Israel

13. Department of Obstetrics and Gynecology, University hospital St. Poelten-Lilienfeld, Austria

14. Second Department of Obstetrics and Gynecology, Aretaieio Hospital, Medical School, National and Kapodistrian University of Athens, Greece

15. Women's Centre, John Radcliffe Hospital, Oxford OX3 9DU, UK

\section{Corresponding author}

Antonio Cano

Department of Pediatrics, Obstetrics and Gynecology, University of Valencia and INCLIVA, Valencia, Spain

Email: Antonio.Cano@uv.es 


\section{Abstract}

Introduction: Globally, 985 million women are aged 50 and over, leading to increasing concerns about chronic conditions such as cardiovascular disease, osteoporosis, dementia, and cognitive decline, which can adversely affect quality of life and independent living.

Aim: To evaluate the evidence from observational studies and randomized trials on the effects of the

Mediterranean diet on short- and long-term menopausal health: estrogen deficiency symptoms, cardiovascular disease, osteoporosis, cognitive and mental health, breast cancer, and all-cause mortality.

Materials and methods: Literature review and consensus of expert opinion.

Summary recommendations: The Mediterranean diet is a non-restrictive dietary pattern common in the olivegrowing areas of the Mediterranean basin. It may improve vasomotor symptoms, cardiovascular risk factors such as blood pressure, cholesterol and blood glucose levels, as well as mood and symptoms of depression. Long-term adherence may: improve cardiovascular risk and events, and death; improve bone mineral density; prevent cognitive decline; and reduce the risk of breast cancer and all-cause mortality.

Key words: Mediterranean diet, health, non-communicable disease, menopause, women's health.

\section{Introduction}

Women are living longer. The United Nations has estimated that, worldwide, 985 million women in 2020 are aged 50 and over. The figure is expected to rise to 1.65 billion by 2050 [1]. Not surprisingly, the immediate and long-term sequelae of postmenopausal estrogen deficiency and aging present an enormous problem to healthcare systems. There are increasing concerns about non-communicable diseases (NCDs) such as cardiovascular disease (CVD), osteoporosis, dementia, and cognitive decline, which can adversely affect quality of life and independent living.

The optimization of diet is increasingly being accepted as playing a role in the strategies to reduce the risk of NCDs and to promote women's health at the menopause. The concept has been recognized worldwide [2]. The EAT-Lancet Commission $[3,4]$ has promoted the concept that a nutritionally optimal dietary pattern is compatible with the United Nations Sustainable Developmental Goals [5]. In addition to meeting age- and gender-related nutrient requirements, there has been increasing focus on the other health benefits of specific dietary patterns, such as the Mediterranean $\operatorname{diet}$ (MedDiet) [6].

Growing international interest in the MedDiet has led to many large observational studies with follow-up extending over decades as well as randomized controlled trials (RCTs). These have found a causal link between the MedDiet and health outcomes $[7,8,9]$. Overall, both all-cause and cause-specific mortality are reduced by the MedDiet $[10,11,12]$. Further, the MedDiet has been shown to be feasible in non-Mediterranean populations, with some health services implementing it within "usual care" for NCDs $[6,13,14,15,16,17]$.

This position statement considers evidence from observational studies and RCTs which examine the MedDiet and focuses on its role in women's post-reproductive health. It considers the effects of the MedDiet on short-term and long-term menopausal health: estrogen deficiency symptoms, cardiovascular disease, osteoporosis, cognitive and mental health, breast cancer and all-cause mortality. 


\section{Composition of the Mediterranean diet}

The MedDiet is the dietary pattern prevailing in the olive-growing areas of the Mediterranean basin; it has been influenced by various civilizations over the centuries [18]. In classical Greece and then in the Roman Empire it was based on bread, olive oil, and wine [19]. The Arabs and the Turkish Empire introduced spices from the Orient, and the role of legumes, grains and nuts was reinforced. New components of the region's diet came with the discovery of the Americas, which introduced a variety of foods, including tomatoes, chilies, and new varieties of legumes. The dietary pattern is plant-dominant, characterized by daily consumption of fruit, vegetables, breads, other forms of cereals, beans and seeds, with olive oil and nuts as the principal source of fat. Dairy products (principally cheese and yogurt), eggs and fish are also eaten. Fish consumption varies with distance to the sea. The MedDiet includes low to moderate wine intake with meals, and some meat, usually poultry (chicken), rabbit, lamb, or goat. The MedDiet is low in saturated fat as olive oil and nuts are the major source of fat [19]. In addition, an important feature of the diet is frugality, imposed by the scarcity of food during winter or during periods of austerity. Also, many of those who adopt the MedDiet are physically active. As the MedDiet is not based on dietary restriction and reflects the usual dietary pattern of diverse cultures, adherence is often higher than to other diets, such as the Dietary Approaches to Stop Hypertension (DASH) diet [6].

\section{The Mediterranean diet and menopausal symptoms}

A single cohort study has examined the effect of the MedDiet on vasomotor symptoms (VMS), such as hot flushes and night sweats, and there is a paucity of data on other estrogen-deficiency symptoms, such as those due to vulvovaginal atrophy. A cohort of over 6,000 women who had passed through a natural menopause in Australia found that adherence to a MedDiet decreased the risk of experiencing VMS by $20 \%(\mathrm{OR}: 0.80$ [95\% Cl: $0.69-0.92] \mathrm{P}<0.001)[20]$.

The Women's Health Initiative ( $n=6,104$ post-menopausal women with VMS) RCT delivered intensive education and counselling to achieve a dietary pattern with high plant intake similar to the MedDiet. In women with mild VMS, the plant-based diet increased the likelihood of elimination of VMS within 12 months by $14 \%$ (OR: 1.14 [95\%Cl: 1.01-1.28] $P=0.04)$; however, there was no improvement for women with moderate to severe VMS [21, 22]. The Study of Women's Health Across the Nation (SWAN) obtained negative results when looking the effect of nutrients in general on VMS in pre- and peri-menopausal women [23], suggesting it is the broader dietary pattern rather than meeting nutrient requirements which affects VMS.

\section{The Mediterranean diet and cardiovascular disease}

Cardiovascular disease has traditionally been seen as more of a men's problem [24]. However, CVD, including both coronary heart disease (CHD) and stroke, is the main cause of death in women worldwide. The World Health Organization estimated that, in 2015, CVD was responsible for 31\% of all global deaths (17.7 million deaths) [25]. In Europe, CVD is responsible for 2.1 million deaths (49\% of all deaths) in women annually [26]. Not surprisingly, the main research focus regarding the benefits of the MedDiet has been on CVD. The first study was the observational Seven Countries Study, initiated after low rates of CHD in Naples were noted in the early 1950s [8]. It investigated the association of the MedDiet with CHD and stroke [9] and was followed by numerous observational studies and RCTs internationally. The latter studies tended to be more sophisticated in adjusting for variables such as body weight which affect CVD risk. 


\section{Observational studies}

The largest and longest observational studies which examine the MedDiet and CVD are shown in Table 1. All the studies found that adherence to the MedDiet reduced the incidence and mortality of CVD. Studies which examined outcomes according to sex reported stronger findings in women [27,28]. Furthermore, systematic reviews and metaanalyses have found mean relative risks of CVD around 0.70 and 0.80 in comparisons of women following the MedDiet and those not $[29,30,31,32,33,34]$.

Synthesizing these findings, a recent meta-analysis of observational studies found that high adherence to the MedDiet by women reduced their relative risk of CHD and acute myocardial infarction (MI) by $30 \%$ and of stroke by $17 \%[24]$ 
Table 1: Observational studies which examine the association between a Mediterranean dietary pattern and cardiovascular disease and all-cause mortality.

\begin{tabular}{|c|c|c|c|c|c|c|}
\hline Study & Country & Sample size & $\begin{array}{l}\text { Percent } \\
\text { female }\end{array}$ & Follow-up duration & Effect of MedDiet in total sample & Effect of MedDiet in women only \\
\hline $\begin{array}{l}\text { Northern Manhattan Study } \\
\text { (Gardener et al., 2011)[35] }\end{array}$ & $\begin{array}{l}\text { United States of } \\
\text { America }\end{array}$ & 2,568 & 64 & 9 years & $\begin{array}{l}\text { Inverse association: } \\
\quad \begin{array}{l}\text { Composite outcome: Ischemic stroke, myocardial } \\
\text { infarction, or CVD-death. } \\
\quad \text { CVD-death }\end{array} \\
\text { No effect: Myocardial infarction, ischemic stroke. }\end{array}$ & Not reported. \\
\hline $\begin{array}{l}\text { European Prospective Investigation into } \\
\text { Cancer (EPIC)-NL } \\
\text { (Hoevenaar-Blom et al., 2012)[36] }\end{array}$ & Netherlands & 34,708 & 75 & $10-15$ years & $\begin{array}{l}\text { Inverse association: } \\
-\quad \text { CVD-death } \\
-\quad \text { CVD } \\
-\quad \text { Myocardial infarction } \\
-\quad \text { Stroke } \\
\text { No effect: angina pectoris, transient ischemic attach, peripheral arterial } \\
\text { disease. }\end{array}$ & Not reported. \\
\hline $\begin{array}{l}\text { European Prospective Investigation into } \\
\text { Cancer (EPIC)-Norfolk } \\
\text { (Tong et al., 2016) [37] }\end{array}$ & United Kingdom & 23,902 & Not reported. & 12.2 years & $\begin{aligned} \text { Inverse association: } \\
-\quad \text { CVD } \\
-\quad \text { CVD-death } \\
-\quad \text { Composite outcome: ischemic heart disease, all-cause } \\
\text { mortality. }\end{aligned}$ & Not reported. \\
\hline $\begin{array}{l}\text { Swedish Mammography Cohort Study } \\
\text { (Tektonidis et al., 2015) [38] }\end{array}$ & Sweden & 32,921 & 100 & 10.4 years & Not applicable. & $\begin{array}{cl}\text { Inverse association: } \\
-\quad & \text { Myocardial infarction } \\
- & \text { Heart failure } \\
- & \text { Ischemic stroke } \\
\text { No effect: haemorrhagic stroke }\end{array}$ \\
\hline $\begin{array}{l}\text { Västerbotten Intervention Program (VIP) } \\
\text { population study (Tognon et al 2012)[39] }\end{array}$ & Sweden & 77,151 & 51 & 10 years & $\begin{array}{l}\text { Inverse association: } \\
-\quad \text { All-cause mortality } \\
\text { No effect: CVD }\end{array}$ & $\begin{array}{c}\text { Inverse association: } \\
-\quad \text { CVD }\end{array}$ \\
\hline $\begin{array}{l}\text { Seguimiento Universidad de Navarra (SUN) } \\
\text { cohort } \\
\text { (Carlos S et al., 2018) [40] }\end{array}$ & Spain & 22,786 & 61 & Since 1999 & $\begin{array}{cl}\text { Inverse association: } \\
- & \text { All-cause mortality } \\
- & \text { CVD } \\
- & \text { CVD-death } \\
\end{array}$ & Not reported. \\
\hline $\begin{array}{l}\text { Women's Health Initiative } \\
\text { (Hirahatake et al., 2019) [41] }\end{array}$ & $\begin{array}{l}\text { United States of } \\
\text { America }\end{array}$ & 5,809 & 100 & 12.4 years & Not applicable. & $\begin{array}{cc}\text { Inverse association: } \\
- & \text { CVD } \\
- & \text { CHD } \\
- & \text { Stroke }\end{array}$ \\
\hline $\begin{array}{l}\text { NutriNet-Santé cohort } \\
\text { (Trébuchet et al., 2019) [42] }\end{array}$ & France & 94,113 & 79 & 5.4 years & $\begin{array}{ll}\text { Inverse association: } \\
-\quad \text { CVD } \\
-\quad \text { Angioplasty } \\
-\quad \text { Angina } \\
\text { No effect: } \text { Myocardial infarction, acute coronary syndrome, stroke. }\end{array}$ & Not reported. \\
\hline $\begin{array}{l}\text { Greek European Investigation into Cancer } \\
\text { and Nutrition cohort (EPIC) } \\
\text { (Dilis et al 2012; Misirli et al 2012) [27, 28] }\end{array}$ & Greece & 23,929 & 58 & 15.8 years & $\begin{array}{ll}\text { Inverse association: } \\
-\quad \text { CHD-death } \\
-\quad \text { Cerebrovascular disease } \\
-\quad \text { Cerebrovascular disease-death } \\
\text { No effect: CHD }\end{array}$ & $\begin{array}{l}\text { Inverse association: } \\
-\quad \text { CDD-death } \\
-\quad \text { CHD } \\
-\quad \text { Cerebrovascular disease } \\
-\quad \text { Cerebrovascular disease-death } \\
\text { Stronger associations than in men. }\end{array}$ \\
\hline $\begin{array}{l}\text { Seven Countries Study } \\
\text { (Menotti et al 2012) [43] }\end{array}$ & Italy & 1,139 & 0 & 5 years & $\begin{array}{c}\text { Inverse association: } \\
-\quad \text { CHD-death } \\
\end{array}$ & Not applicable. \\
\hline $\begin{array}{l}\text { MONItoring trends and determinants of } \\
\text { Cardiovascular } \\
\text { population study } \\
\text { Tognoase et al 2013 [44] }\end{array}$ & Denmark & 1,849 & 51 & 11 years & $\begin{array}{l}\text { Inverse association: } \\
-\quad \text { CVD } \\
-\quad \text { Myocardial infarction } \\
-\quad \text { All-cause mortality } \\
\text { No effect: Stoke }\end{array}$ & Not reported. \\
\hline
\end{tabular}

CHD, coronary heart disease; CVD, cardiovascular disease. 


\section{Randomized controlled trials}

The study that has received the most interest has been the PREvención con Dieta MEDiterránea (PREDIMED) study [45]. A primary prevention RCT, PREDIMED examined whether the unrestricted-calorie MedDiet was superior to a low-fat diet for CVD protection in older men and postmenopausal women with CVD risk factors. The 7,447 participants $(57 \%$ women) were randomized to one of three arms, two of them consisting of the MedDiet, one supplemented with extra-virgin olive oil and the other with nuts, and the third consisting of a low-fat diet. Energy restriction was not advised, nor was physical activity promoted. The primary objective was to measure the rate of clinical CVD events such as myocardial infarction (MI) and stroke, and CVD death. The study was prematurely stopped after 4.8 years of follow-up due to the clear benefits observed in both the olive oil (HR: 0.69 [95\%Cl: 0.53-0.91]) and nut arms (HR: 0.72 [95\% Cl: 0.54-0.95]). Consequently, PREDIMED has become a landmark study because, for the first time, it observed a clear causal association between MedDiet and objective CVD outcomes. However, gender differences were not reported.

The Lyon Heart Study was a secondary prevention RCT in men and women aged under 70 years who had experienced a first MI. It investigated whether a MedDiet enriched with alpha-linoleic acid reduced the rates of cardiac death and non-fatal acute MI [46]. After a mean follow-up of 27 months, the risk ratio for the two main endpoints combined was 0.27 (95\% Cl: 0.12-0.59) and overall mortality 0.30 (95\% Cl: 0.11-0.82) in the MedDiet group. Differences between women and men were not presented.

The Mediet Project randomized trial, with a sample of postmenopausal women, examined the effects of providing MedDiet cooking lessons with the instruction to use these skills at home. After 1 year, participants in the intervention group had improved their cholesterol levels and quality of life compared with the controls [47].

A 2019 Cochrane systematic review that analyzed data from 30 RCTs, in both sexes and all age groups, including the above-mentioned RCTs, concluded that the trial evidence on the effectiveness of the MedDiet in the risk reduction or management of CVD was still uncertain due to statistical heterogeneity $[48,49]$. On the other hand, recommending an eating style can help women make positive changes. The MedDiet is included in nutrition guidelines to promote health and decrease CVD burden $[16,17,50]$.

\section{The Mediterranean diet and cardiovascular risk factors}

\section{Blood pressure}

The effect of the MedDiet on blood pressure has been investigated in both healthy and hypertensive individuals. There is a consensus that the MedDiet does decrease blood pressure but that the size of the effect is small. Observational studies have shown reductions of $2-3 \mathrm{mmHg}$ and $1-2 \mathrm{mmHg}$ in mean systolic and diastolic blood pressure, respectively [51]. The Hellenic National Nutrition and Health Survey (2013-2015, n=1040) found that stricter MedDiet adherence decreased the odds of being hypertensive by $36 \%$ [52]. Randomized trials have found similar small reductions in blood pressure with the MedDiet $[53,54,55]$. 
Lipids

Evidence from RCTs shows that the MedDiet is associated with beneficial, although small, lipid changes. A reduction of up to $0.2 \mathrm{mmol} / \mathrm{L}(7.7 \mathrm{mg} / \mathrm{dL})$ has been found for total cholesterol and low-density lipoprotein cholesterol but little or no effect on high-density lipoprotein cholesterol has been found [48].

The PREDIMED study has generated a number of sub-studies in which changes in lipoproteins have been investigated $[56,57,58]$. Most of them support shifts in lipoprotein subfractions to a less atherogenic pattern, but more evidence is required regarding the effect specifically for menopausal and postmenopausal women. The Mediet Project RCT (see above), which recruited postmenopausal women, found a trend towards improved cholesterol levels in the MedDiet intervention group, compared with controls; however, specific levels were not reported [47].

\section{Central obesity and fat distribution}

Central obesity is associated with chronic low-grade inflammation, and is a risk factor for cardiometabolic syndrome. It has been investigated as one of the outcomes of the MedDiet. The conclusions from some studies are unclear as some MedDiets were low in calorie as well. Thus it is hard to assess whether any effects seen were the result of the foods included in the diet or the calorie restriction [see for example 59]. Analysis of intervention trials overall shows that the MedDiet prevents an increase in central obesity [60]. Changes in waist circumference range between $0.5 \mathrm{~cm}$ and $7 \mathrm{~cm}$. In RCTs which recruited only women, waist circumference decreased by $5.2-6.5 \mathrm{~cm}$. Improvements in waist-hip ratio were also noted. A limited effect on waist circumference was observed in the unrestricted-calorie high-vegetable-fat MedDiet PREDIMED study [61]. Thus, the adjusted difference in 5-year changes in waist circumference was $-0.466 \mathrm{~cm}(-1.109$ to $0.176 ; p=0.154)$ in the MedDiet with olive oil group and $0.923 \mathrm{~cm}(-1.604$ to $-0.241 ; p=0 \cdot 008)$ in the MedDiet with nut group, compared with the control group.

Two randomized studies have provided information about fat distribution. One, using magnetic resonance imaging, found that a Mediterranean/low-carbohydrate diet mobilized specific ectopic fat depots, decreasing intrahepatic, intrapericardial, and pancreatic fat deposition [62]. Another study with dual-energy X-ray absorptiometry (DXA) found a reduction in subcutaneous fat and waist circumference but not visceral adipose tissue or other body composition measures [63].

\section{Type 2 diabetes mellitus and metabolic syndrome}

A cluster of risk factors for CVD and type 2 diabetes mellitus, which occur together more often than by chance alone, are known as the metabolic syndrome. The risk factors include raised blood pressure, dyslipidemia (raised triglycerides and low-density lipoprotein [LDL] cholesterol and lowered high-density lipoprotein [HDL] cholesterol), raised fasting glucose, and central obesity [64]. The effect of the MedDiet on metabolic syndrome has been widely examined in observational and intervention studies.

A meta-analysis of observational studies concluded that adherence to the MedDiet in women is not significantly associated with a reduced risk of metabolic syndrome. However, the subgroup analysis of women was based only on two of the 14 included studies, and the finding for combined sexes showed a substantial reduction of 19\% (RR: 81\% [95\% Cl: 0.71-0.92]) [65]. Other meta-analyses, which included both epidemiological and intervention studies, came to a similar result for combined sexes, but did not explore the effect in women alone [66,67]. Two MedDiet RCTs 
which were conducted exclusively in postmenopausal women found significant improvements in HDL cholesterol, triglycerides, blood pressure, glucose, and insulin sensitivity $[68,69]$.

Meta-analyses of the effect of the MedDiet on metabolic syndrome found that fasting glucose levels were slightly reduced, by about 0.1-0.3 $\mathrm{mmol} / \mathrm{L}(2-6 \mathrm{mg} / \mathrm{dL})[66,67]$. In a sample of postmenopausal women, it was reduced by $0.4 \mathrm{mmol} / \mathrm{L}(7 \mathrm{mg} / \mathrm{dL})[68]$.

A meta-analysis of prospective studies of dietary patterns and type 2 diabetes found that adherence to the MedDiet (RR comparing extreme quantiles: 0.87 [95\% Cl: 0.82-0.93]), as well as to the experimental interventions in the Dietary Approaches to Stop Hypertension (DASH) (RR: 0.81 [95\%Cl: 0.72-0.92]) and the Alternative Healthy Eating Index (AHEI) studies (RR: 0.79 [95\% Cl: 0.69-0.90]), were associated with significant risk reductions in the incidence of type 2 diabetes. [70]. The US Atherosclerosis Risk in Communities study prospective cohort without diabetes, cardiovascular disease, or cancer at baseline $(n=11,991$, mean age 54 years at study entry, $56 \%$ female, $75 \%$ white) with a median follow-up of 22 years also found lower diabetes risk with the MedDiet. [71]. Furthermore, associations were stronger for black versus white participants and weaker for obese versus those with normal body mass index (BMI), but there was no difference in the effect according to sex.

A systematic review of all meta-analyses and RCTs with electronic searches up to January 2015 concluded that the MedDiet was associated with better glycemic control and cardiovascular risk factors than control diets, including lower-fat diets, suggesting that it is suitable for the overall management of type 2 diabetes in both sexes [72]. A subsequent network meta-analysis of randomized trials found that the MedDiet produced beneficial improvements in glycemic control, weight loss, and cardiovascular risk factors in people with type 2 diabetes [73]. An RCT which included women (mean age 50 years) newly diagnosed with type 2 diabetes compared the MedDiet with a low-fat diet. Reductions in weight, glycated hemoglobin (HbA1c) and systolic blood pressure were significantly greater in the MedDiet group than in the low-fat group [74].

In summary, adherence to the MedDiet reduces the risk of developing type 2 diabetes and improves its course, both in peri- or postmenopausal women and in men. Although the effects are small, the MedDiet may be preferable to restrictive diets such as a low-fat diet. Further observational studies and RCTs in peri- and postmenopausal women are required to improve the quality of the evidence.

\section{The Mediterranean diet and osteoporosis}

As the burden of osteoporotic fracture in terms of both mortality and disability is increasing, not surprisingly the effect of nutrition on bone health has attracted considerable attention [75]. Adequate intakes of calcium and vitamin D are recommended in most osteoporosis guidelines [76] and there is growing interest on the role of protein intake in bone accrual during childhood and adolescence and skeletal preservation in the post reproductive years $[77,78]$.

A post-hoc analysis of the Women's Health Initiative observational study published in 2016 found that women scoring in the highest quintile of the MedDiet had a $20 \%$ lower risk of hip, but not total, fracture [79]. A meta-analysis published in 2017 of three prospective cohort studies, including the Women's Health Initiative observational study 
[79], concluded that only observational evidence on the effect of the MedDiet on bone health was available and that there was lack of agreement in the findings for hip fracture [80].

Subsequently, a one-year randomized trial undertaken across five European centers with 1294 participants (mean \pm SD age: $70.9 \pm 4.0$ years; $46 \%$ women) of a Mediterranean-like dietary pattern and a vitamin D3 supplement (400 IU /d) found no effect on bone mineral density (BMD) (site-specific or whole-body) [81]. Osteoporotic fracture was not evaluated. Subgroup analysis of individuals with osteoporosis at baseline (site-specific BMD T-score $\leq-2.5$ SDs) showed that the MedDiet attenuated the expected decline in femoral neck bone mineral density ( $n=24$ and 30 in the MedDiet and control groups, respectively; $P=0.04$ ) but had no effect on lumbar spine or whole-body parameters. The authors concluded that the intervention had no effect on BMD in the normal age-related range, but significantly reduced the rate of loss of bone at the femoral neck in individuals with osteoporosis. Thus, further research is needed regarding the MedDiet and skeletal health and osteoporotic fracture; however, the MedDiet may be considered an appropriate diet for women with osteoporosis but should not be used as the primary treatment strategy.

\section{The Mediterranean diet and cognitive and mental health}

In 2017 it was estimated that 792 million people lived with a mental health disorder. This is slightly more than one in 10 people globally ( $10.7 \%$ overall, $9.3 \%$ of men and $11.9 \%$ of women) [82]. Research on the effects of the MedDiet on cognition and mood disorders is summarized below.

\section{Cognition}

Dementia has become a public health priority: in 2016, the global number of individuals living with dementia was 43.8 million, having increased from 20.2 million in 1990. More women than men had dementia in 2016 (27.0 million vs 16.8 million), and dementia was the fifth leading cause of death globally, accounting for 2.4 million deaths [83]. The World Health Organization has recognized diet as an important factor in reducing the risk of cognitive decline and dementia (84). Several cohort studies have been undertaken. A 2014 meta-analysis with five eligible studies found that in cognitively normal individuals, higher adherence to the MedDiet was associated with a reduced risk of mild cognitive impairment (HR: 0.73 [95\% Cl: 0.56-0.96]; $\mathrm{P}=0.02$ ) and Alzheimer's disease (HR: 0.64 [95\%Cl: 0.46-0.89]; $\mathrm{P}=0.007$ ]) [85]. In a 2017 systematic review and meta-analysis of nine cohort studies with a total of 34,168 participants, the pooled analysis showed that the highest MedDiet category score, compared with the lowest category, was inversely associated with the development of cognitive disorders, and the pooled RR was $0.79(95 \% \mathrm{Cl}$ : 0.70-0.90) [86]. Protective effects have been reported in subsequent cohort studies undertaken in Europe, the USA and China $[87,88,89]$. Furthermore, higher self-reported MedDiet adherence is associated with beneficial effects on cognitive and neuroimaging phenotypes associated with Alzheimer's disease [90].

A prospective cohort study of 16,058 postmenopausal women found that long-term adherence to a MedDiet pattern was linearly associated with improved cognitive scores in adjusted models [91]. However, in a study of 2,504 periand postmenopausal women with CVD, which per se increases the risk of cognitive decline, greater short-term adherence to the MedDiet had no effect on cognition [92]. This aligns with other findings regarding diet and cognition. For instance, long-term adherence to a diet that includes frequent consumption of fish, such as the traditional MedDiet, is associated with improved cognition, but short-term interventions, whether dietary or supplemental, have no effect [93]. 


\section{Mood and depression}

The important effect of diet on mood is such that lifestyle and dietary changes are incorporated in psychiatric clinical practice guidelines [ see for example 94]. Systematic reviews and meta-analyses have found that adherence to the MedDiet reduces the risk of depression [ see for example 95,96,97,98,99,100]. However, the Whitehall II Study could not detect an effect of the MedDiet on the recurrence of depressive symptoms [101]. Nevertheless, the SUN study, which followed individuals free of depression at baseline, found that adherence to the MedDiet (comparison of the highest vs the lowest quartile) was associated with a $25 \%$ mean reduction in depression diagnoses at two-year followup [102]. Furthermore, the Women's Health Initiative Observational Study found that a diet with a high glycemic index was a risk factor for depression [103].

A well-controlled RCT which recruited participants with major depressive disorder, mostly women in the early perimenopause, found that adherence to the MedDiet for 3 months significantly improved depressive symptoms as well as depression remission, with a number needed to treat of 4.1 (95\% Cl: 2.3-27.8) [104].

\section{The Mediterranean diet and breast cancer}

Reports on a possible association between the MedDiet and the risk of breast cancer have been contradictory [105]. The EPIC cohort study, drawing on populations across Europe, found an inverse association with the risk of breast cancer in postmenopausal women (HR: 0.93 [95\% Cl: 0.88-1.00]) [106]. The Swedish Women's Lifestyle and Health cohort reported no association [107]. Whilst a Western-style dietary pattern was found to increase the risk of breast cancer, a case-control study found that high adherence to the MedDiet decreased the risk (OR: 0.56 [95\% Cl: $0.40-$ 0.79]) [108]. The PREDIMED randomized trial reported that after 4.8 years, the MedDiet supplemented with olive oil significantly decreased the risk of breast cancer by $69 \%$ (HR: 0.31 [95\% Cl: $0.23-0.77]$ ), but no statistically significant effect was found for the MedDiet supplemented with nuts [109]. Furthermore, the Women's Health Initiative Dietary Modification Randomized Trial found that adoption of a low-fat diet with increased vegetable, fruit, and grain intake may reduce the risk of death as a result of breast cancer in postmenopausal women [110]. Inverse associations have been reported between the MedDiet and breast cancer subtypes, including ER-/PR- tumors (HR: 0.80 [95\%Cl: 0.65$0.99])$ and triple-negative tumors (OR: 0.32 [95\% Cl: 0.15-0.66]) [106,108].

\section{The Mediterranean diet and all-cause mortality}

As shown in Table 1, the MedDiet has been found to be inversely associated with both CVD-related and all-cause mortality in both Mediterranean and non-Mediterranean populations [12,111]. Furthermore, a systematic review and meta-analysis in 2019 involving 29 prospective studies with 1,676,901 participants, 221,603 of whom died in the study period, found that the risk of all-cause mortality linearly decreased with increase in adherence to a MedDiet [10]. 


\section{Summary}

The MedDiet is a non-restrictive dietary pattern which has proved broadly acceptable to non-Mediterranean as well as Mediterranean populations. While there is not one exact MedDiet, the defining characteristics include: high intake of olive oil, nuts, vegetables, fruits, and cereals; moderate intake of fish and poultry; low intake of dairy products, red meat, processed meats, and sweets; and wine in moderation, consumed with meals.

In peri- and post-menopausal women, long-term high adherence may:

- reduce cardiovascular risk, and the incidence of cardiovascular events and death

- maintain bone mineral density whilst leading to more favorable body composition

- improve bone mineral density in women with osteoporosis

- help to prevent cognitive decline

- reduce the risk of breast cancer

- reduce the risk of all-cause mortality.

In peri- and post-menopausal women, short-term high adherence may:

- improve vasomotor symptoms

- improve cardiovascular risk factors such as blood pressure, cholesterol, and blood glucose levels

- improve mood and symptoms of depression.

\section{Contributors}

Antonio Cano, Skye Marshall, Irene Zolfaroli, and Margaret Rees prepared the initial draft, which was circulated to all other named authors (EMAS board members) for comments and approval; production was coordinated by Irene Lambrinoudaki and Margaret Rees.

\section{Conflict of interest}

Antonio Cano: In the past three years, Dr Antonio Cano has received speakers' honoraria from Shionogi and consulting fees from Pierre-Fabre Iberica and Mitsubishi Tanabe Pharma.

Skye Marshall: In the past three years, Dr Skye Marshall has been partially supported by an Innovation Connections grant (Commonwealth of Australia) and has worked on research projects funded by industry. Dr Marshall declares no conflicts of interest.

Irene Zolfaroli: None declared.

Johannes Bitzer: In the past three years Prof. Bitzer has served on advisory boards of Bayer AG, Merck, MSD, Teva, Theramex, Mithra, Actavis, Ava, Natural cycles, Böhringer Ingelheim, Effik, Lilly, Exeltis, Vifor, Libbs, Gedeon Richter, HRA and has given invited lectures and received honoraria by Bayer Pharma AG, Merck, Johnson and Johnson, Teva, Mylan, Allergan, Abbott, Lilly, Pfizer, Exeltis, Libbs, HRA, Pierre Fabre.

Iuliana Ceausu: None declared.

Peter Chedraui: None declared.

Fatih Durmusoglu: None declared.

Risto Erkkola: None declared. 
Dimitrios G. Goulis: None declared.

Angelica Lindén Hirschberg: None declared.

Ludwig Kiesel: In the past year Prof. Kiesel has received grants/research support from: none, consulting fees from:

AstraZeneca, Novartis, Gedeon Richter, Palleos healthcare, Roche and speakers' honoraria from: AstraZeneca, Novartis, Gedeon Richter, Roche.

Patrice Lopes: None declared.

Amos Pines: None declared.

Mick van Trotsenburg: None declared.

Irene Lambrinoudaki: None declared.

Margaret Rees has received consulting fees in the past three years from Sojournix, Inc.

\section{Funding}

No funding was sought or secured for the preparation of this position statement.

\section{Provenance and peer review}

This article is an EMAS position statement and was not externally peer reviewed.

\section{Acknowledgement}

Peter Chedraui is supported by the Sistema de Investigación y Desarrollo (SINDE) and the Vice-Rectorado de Investigación \& Postgrado (VRIP) of the Universidad Católica de Santiago de Guayaquil, Guayaquil, Ecuador, through grant No. SIU-318-853-2014 (The Omega II, Women's Health Project). Neither SINDE nor VRIP have had involvement in the writing of this position statement.

\section{References}

1. United Nations World Population Prospects 2019 https://population.un.org/wpp/ [Accessed 17 June 2020]

2. Afshin A, Micha R, Webb M, et al. Effectiveness of Dietary Policies to Reduce Noncommunicable Diseases. In: Prabhakaran D, Anand S, Gaziano TA, Mbanya JC, Wu Y, Nugent R, eds. Cardiovascular, Respiratory, and Related Disorders. 3rd ed. Washington (DC): The International Bank for Reconstruction and Development / The World Bank; 2017.

3. Willett W, Rockström J, Loken B, et al. Food in the Anthropocene: the EAT-Lancet Commission on healthy diets from sustainable food systems [published correction appears in Lancet. 2019 Feb 9;393(10171):530] [published correction appears in Lancet. 2019 Jun 29;393(10191):2590] [published correction appears in Lancet. 2020 Feb 1;395(10221):338]. Lancet. 2019;393(10170):447-492. doi:10.1016/S0140-6736(18)31788-4

4. Lucas T, Horton R. The 21st-century great food transformation. Lancet. 2019;393(10170):386-387. doi:10.1016/S0140-6736(18)33179-9

5 United Nations https://www.un.org/sustainabledevelopment/sustainable-development-goals/ [Accessed 17 June 2020]

6. Marshall S., Rees M. (2019) Managing Menopause and Post-reproductive Health: Beyond Hormones and Medicines. In: Pérez-López F. (eds) Postmenopausal Diseases and Disorders. Springer, Cham. doi.org/10.1007/978-3-030-13936-0_29 
7. Hidalgo-Mora JJ, García-Vigara A, Sánchez-Sánchez ML, García-Pérez MÁ, Tarín J, Cano A. The Mediterranean diet: A historical perspective on food for health. Maturitas. 2020;132:65-69. doi:10.1016/j.maturitas.2019.12.002

8. Keys A. Mediterranean diet and public health: personal reflections. Am J Clin Nutr. 1995;61(6 Suppl):1321S1323S. doi:10.1093/ajen/61.6.1321S

9. Menotti A, Puddu PE. How the Seven Countries Study contributed to the definition and development of the Mediterranean diet concept: a 50-year journey. Nutr Metab Cardiovasc Dis. 2015;25(3):245-252.

doi:10.1016/j.numecd.2014.12.001

10. Soltani S, Jayedi A, Shab-Bidar S, Becerra-Tomás N, Salas-Salvadó J. Adherence to the Mediterranean Diet in Relation to All-Cause Mortality: A Systematic Review and Dose-Response Meta-Analysis of Prospective Cohort Studies. Adv Nutr. 2019;10(6):1029-1039. doi:10.1093/advances/nmz041

11. SchwingshackI L, Schwedhelm C, Galbete C, Hoffmann G. Adherence to Mediterranean Diet and Risk of Cancer: An Updated Systematic Review and Meta-Analysis. Nutrients. 2017;9(10):1063. Published 2017 Sep 26. doi:10.3390/nu9101063

12. Warensjö Lemming E, Byberg L, Wolk A, Michaëlsson K. A comparison between two healthy diet scores, the modified Mediterranean diet score and the Healthy Nordic Food Index, in relation to all-cause and cause-specific mortality. Br J Nutr. 2018;119(7):836-846. doi:10.1017/S0007114518000387

13. Lara J, Turbett E, Mckevic A, Rudgard K, Hearth H, Mathers JC. The Mediterranean diet among British older adults: Its understanding, acceptability and the feasibility of a randomised brief intervention with two levels of dietary advice. Maturitas. 2015;82(4):387-393. doi:10.1016/j.maturitas.2015.07.029

14. George ES, Kucianski T, Mayr HL, Moschonis G, Tierney AC, Itsiopoulos C. A Mediterranean Diet Model in Australia: Strategies for Translating the Traditional Mediterranean Diet into a Multicultural Setting. Nutrients. 2018;10(4):465. Published 2018 Apr 9. doi:10.3390/nu10040465

15. Metro South Health. 2019. Plant-based proving positive at PA Hospital. https://metrosouth.health.qld.gov.au/news/plant-based-proving-positive-at-pa-hospital. [Accessed 17 June 2020]

16. Australian Dietary Guidelines. Canberra: NHMRC, Australian Government; 2013.

https://www.nhmrc.gov.au/guidelines-publications/n55

[Accessed 17 June 2020]

17. Canada's Dietary Guidelines https://food-guide.canada.ca/en/guidelines/what-are-canadas-dietary-guidelines/ [Accessed 17 June 2020]

18. Trichopoulou A, Martínez-González MA, Tong TY, et al. Definitions and potential health benefits of the Mediterranean diet: views from experts around the world. BMC Med. 2014;12:112. Published 2014 Jul 24. doi:10.1186/1741-7015-12-112

19. Radd-Vagenas S, Kouris-Blazos A, Singh MF, Flood VM. Evolution of Mediterranean diets and cuisine: concepts and definitions. Asia Pac J Clin Nutr. 2017;26(5):749-763. doi:10.6133/apjcn.082016.06

20. Herber-Gast GC, Mishra GD. Fruit, Mediterranean-style, and high-fat and -sugar diets are associated with the risk of night sweats and hot flushes in midlife: results from a prospective cohort study. Am J Clin Nutr. 2013;97(5):1092-1099. doi:10.3945/ajcn.112.049965

21. Kroenke $\mathrm{CH}$, Caan BJ, Stefanick ML, et al. Effects of a dietary intervention and weight change on vasomotor symptoms in the Women's Health Initiative. Menopause. 2012;19(9):980-988. doi:10.1097/gme.0b013e31824f606e

22. Reame NK. Fat, fit, or famished? No clear answers from the Women's Health Initiative about diet and dieting for longstanding hot flashes. Menopause. 2012;19(9):956-958. doi:10.1097/gme.0b013e318263859a

23. Gold EB, Block G, Crawford S, et al. Lifestyle and demographic factors in relation to vasomotor symptoms: baseline results from the Study of Women's Health Across the Nation. Am J Epidemiol. 2004;159(12):1189-1199. doi:10.1093/aje/kwh168 
24. Woodward M. Cardiovascular Disease and the Female Disadvantage. Int J Environ Res Public Health. 2019;16(7):1165. Published 2019 Apr 1. doi:10.3390/ijerph16071165

25. World Health Organization. Cardiovascular diseases (CVDs) Fact sheet Updated May 2017 http://www.who.int/mediacentre/factsheets/fs317/en/ [Accessed 17 June 2020 ]

26. European Cardiovascular Disease Statistics 2017 edition http://www.ehnheart.org/cvd-statistics.html

[Accessed 17 June 2020]

27. Dilis V, Katsoulis M, Lagiou P, Trichopoulos D, Naska A, Trichopoulou A. Mediterranean diet and CHD: the Greek European Prospective Investigation into Cancer and Nutrition cohort. Br J Nutr. 2012;108(4):699-709. doi:10.1017/S0007114512001821

28. Misirli G, Benetou V, Lagiou P, Bamia C, Trichopoulos D, Trichopoulou A. Relation of the traditional Mediterranean diet to cerebrovascular disease in a Mediterranean population. Am J Epidemiol. 2012;176(12):11851192. doi:10.1093/aje/kws205

29. Kontogianni MD, Panagiotakos DB. Dietary patterns and stroke: a systematic review and re-metaanalysis. Maturitas. 2014;79(1):41-47. doi:10.1016/j.maturitas.2014.06.014

30. Bloomfield HE, Koeller E, Greer N, MacDonald R, Kane R, Wilt TJ. Effects on Health Outcomes of a Mediterranean Diet With No Restriction on Fat Intake: A Systematic Review and Meta-analysis. Ann Intern Med. 2016;165(7):491-500. doi:10.7326/M16-0361

31. Grosso G, Marventano S, Yang J, et al. A comprehensive meta-analysis on evidence of Mediterranean diet and cardiovascular disease: Are individual components equal?. Crit Rev Food Sci Nutr. 2017;57(15):3218-3232. doi:10.1080/10408398.2015.1107021

32. Rosato V, Temple NJ, La Vecchia C, Castellan G, Tavani A, Guercio V. Mediterranean diet and cardiovascular disease: a systematic review and meta-analysis of observational studies. Eur J Nutr. 2019;58(1):173-191. doi:10.1007/s00394-017-1582-0

33. Franquesa M, Pujol-Busquets G, García-Fernández E, et al. Mediterranean Diet and Cardiodiabesity: A Systematic Review through Evidence-Based Answers to Key Clinical Questions. Nutrients. 2019;11(3):655. Published 2019 Mar 18. doi:10.3390/nu11030655

34. Salas-Salvadó J, Becerra-Tomás N, García-Gavilán JF, Bulló M, Barrubés L. Mediterranean Diet and Cardiovascular Disease Prevention: What Do We Know?. Prog Cardiovasc Dis. 2018;61(1):62-67. doi:10.1016/j.pcad.2018.04.006

35. Gardener H, Wright CB, Gu Y, et al. Mediterranean-style diet and risk of ischemic stroke, myocardial infarction, and vascular death: the Northern Manhattan Study. Am J Clin Nutr. 2011;94(6):1458-1464.

doi:10.3945/ajcn.111.012799

36. Hoevenaar-Blom MP, Nooyens AC, Kromhout D, et al. Mediterranean style diet and 12-year incidence of cardiovascular diseases: the EPIC-NL cohort study. PLoS One. 2012;7(9):e45458. doi:10.1371/journal.pone.0045458

37. Tong TY, Wareham NJ, Khaw KT, Imamura F, Forouhi NG. Prospective association of the Mediterranean diet with cardiovascular disease incidence and mortality and its population impact in a non-Mediterranean population: the EPIC-Norfolk study. BMC Med. 2016;14(1):135. Published 2016 Sep 29. doi:10.1186/s12916-016-0677-4

38. Tektonidis TG, Åkesson A, Gigante B, Wolk A, Larsson SC. A Mediterranean diet and risk of myocardial infarction, heart failure and stroke: A population-based cohort study. Atherosclerosis. 2015;243(1):93-98. doi:10.1016/j.atherosclerosis.2015.08.039

39. Tognon G, Lissner L, Sæbye D, Walker KZ, Heitmann BL. The Mediterranean diet in relation to mortality and CVD: a Danish cohort study. Br J Nutr. 2014;111(1):151-159. doi:10.1017/S0007114513001931

40. Carlos S, De La Fuente-Arrillaga C, Bes-Rastrollo M, et al. Mediterranean Diet and Health Outcomes in the SUN Cohort. Nutrients. 2018;10(4):439. Published 2018 Mar 31. doi:10.3390/nu10040439 
41. Hirahatake KM, Jiang L, Wong ND, et al. Diet Quality and Cardiovascular Disease Risk in Postmenopausal Women With Type 2 Diabetes Mellitus: The Women's Health Initiative. J Am Heart Assoc. 2019;8(19):e013249. doi:10.1161/JAHA.119.013249

42. Trébuchet A, Julia C, Fézeu L, et al. Prospective association between several dietary scores and risk of cardiovascular diseases: Is the Mediterranean diet equally associated to cardiovascular diseases compared to National Nutritional Scores?. Am Heart J. 2019;217:1-12. doi:10.1016/j.ahj.2019.07.009.

43. Menotti A, Alberti-Fidanza A, Fidanza F. The association of the Mediterranean Adequacy Index with fatal coronary events in an Italian middle-aged male population followed for 40 years. Nutr Metab Cardiovasc Dis. 2012;22(4):369-375. doi:10.1016/j.numecd.2010.08.002

44. Tognon G, Nilsson LM, Lissner L, et al. The Mediterranean diet score and mortality are inversely associated in adults living in the subarctic region. J Nutr. 2012;142(8):1547-1553. doi:10.3945/jn.112.160499

45. Estruch R, Ros E, Salas-Salvadó J, et al. Primary Prevention of Cardiovascular Disease with a Mediterranean Diet Supplemented with Extra-Virgin Olive Oil or Nuts. N Engl J Med. 2018;378(25):e34. doi:10.1056/NEJMoa180038

46. de Lorgeril M, Renaud S, Mamelle N, et al. Mediterranean alpha-linolenic acid-rich diet in secondary prevention of coronary heart disease [published correction appears in Lancet 1995 Mar 18;345(8951):738]. Lancet. 1994;343(8911):1454-1459. doi:10.1016/s0140-6736(94)92580-1

47. Castagnetta L, Granata OM, Cusimano R, et al. The Mediet Project. Ann N Y Acad Sci. 2002;963:282-289. doi:10.1111/j.1749-6632.2002.tb04119.x

48. Rees K, Takeda A, Martin N, et al. Mediterranean-style diet for the primary and secondary prevention of cardiovascular disease. Cochrane Database Syst Rev. 2019;3(3):CD009825. Published 2019 Mar 13. doi:10.1002/14651858.CD009825.pub3

49. Stranges S, Takeda A, Martin N, Rees K. Cochrane corner: does the Mediterranean-style diet help in the prevention of cardiovascular disease?. Heart. 2019;105(22):1691-1694. doi:10.1136/heartjnl-2019-315339

50. Locke A, Schneiderhan J, Zick SM. Diets for Health: Goals and Guidelines. Am Fam Physician. 2018;97(11):721728.

51. Núñez-Córdoba JM, Valencia-Serrano F, Toledo E, Alonso A, Martínez-González MA. The Mediterranean diet and incidence of hypertension: the Seguimiento Universidad de Navarra (SUN) Study. Am J Epidemiol. 2009;169(3):339346. doi:10.1093/aje/kwn335

52. Magriplis E, Panagiotakos D, Kyrou I, et al. Presence of Hypertension Is Reduced by Mediterranean Diet Adherence in All Individuals with a More Pronounced Effect in the Obese: The Hellenic National Nutrition and Health Survey (HNNHS). Nutrients. 2020;12(3):853. Published 2020 Mar 23. doi:10.3390/nu12030853

53. Nissensohn M, Román-Viñas B, Sánchez-Villegas A, Piscopo S, Serra-Majem L. The Effect of the Mediterranean Diet on Hypertension: A Systematic Review and Meta-Analysis. J Nutr Educ Behav. 2016;48(1):42-53.e1. doi:10.1016/j.jneb.2015.08.023

54. Ndanuko RN, Tapsell LC, Charlton KE, Neale EP, Batterham MJ. Dietary Patterns and Blood Pressure in Adults: A Systematic Review and Meta-Analysis of Randomized Controlled Trials. Adv Nutr. 2016;7(1):76-89. Published 2016 Jan 15. doi:10.3945/an.115.009753

55. Gay HC, Rao SG, Vaccarino V, Ali MK. Effects of Different Dietary Interventions on Blood Pressure: Systematic Review and Meta-Analysis of Randomized Controlled Trials. Hypertension. 2016;67(4):733-739. doi:10.1161/HYPERTENSIONAHA.115.06853

56. Solá R, Fitó M, Estruch R, et al. Effect of a traditional Mediterranean diet on apolipoproteins $B, A-I$, and their ratio: a randomized, controlled trial. Atherosclerosis. 2011;218(1):174-180. doi:10.1016/j.atherosclerosis.2011.04.026 
57. Damasceno NR, Sala-Vila A, Cofán M, et al. Mediterranean diet supplemented with nuts reduces waist circumference and shifts lipoprotein subfractions to a less atherogenic pattern in subjects at high cardiovascular risk. Atherosclerosis. 2013;230(2):347-353. doi:10.1016/j.atherosclerosis.2013.08.014

58. Hernáez Á, Castañer O, Elosua R, et al. Mediterranean Diet Improves High-Density Lipoprotein Function in HighCardiovascular-Risk Individuals: A Randomized Controlled Trial. Circulation. 2017;135(7):633-643.

doi:10.1161/CIRCULATIONAHA.116.023712

59. Sofi F, Dinu M, Pagliai G, et al. Low-Calorie Vegetarian Versus Mediterranean Diets for Reducing Body Weight and Improving Cardiovascular Risk Profile: CARDIVEG Study (Cardiovascular Prevention With Vegetarian Diet). Circulation. 2018;137(11):1103-1113. doi:10.1161/CIRCULATIONAHA.117.030088

60. Bendall CL, Mayr HL, Opie RS, Bes-Rastrollo M, Itsiopoulos C, Thomas CJ. Central obesity and the Mediterranean diet: A systematic review of intervention trials. Crit Rev Food Sci Nutr. 2018;58(18):3070-3084. doi:10.1080/10408398.2017.1351917

61. Estruch R, Martínez-González MA, Corella D, et al. Effect of a high-fat Mediterranean diet on bodyweight and waist circumference: a prespecified secondary outcomes analysis of the PREDIMED randomised controlled trial. Lancet Diabetes Endocrinol. 2019;7(5):e6-e17. doi:10.1016/S2213-8587(19)30074-9

62. Gepner Y, Shelef I, Schwarzfuchs D, et al. Effect of Distinct Lifestyle Interventions on Mobilization of Fat Storage Pools: CENTRAL Magnetic Resonance Imaging Randomized Controlled Trial. Circulation. 2018;137(11):1143-1157. doi:10.1161/CIRCULATIONAHA.117.030501

63. Mayr HL, Itsiopoulos C, Tierney AC, et al. Ad libitum Mediterranean diet reduces subcutaneous but not visceral fat in patients with coronary heart disease: A randomised controlled pilot study. Clin Nutr ESPEN. 2019;32:61-69. doi:10.1016/j.clnesp.2019.05.001

64. Alberti KG, Eckel RH, Grundy SM, et al. Harmonizing the metabolic syndrome: a joint interim statement of the International Diabetes Federation Task Force on Epidemiology and Prevention; National Heart, Lung, and Blood Institute; American Heart Association; World Heart Federation; International Atherosclerosis Society; and International Association for the Study of Obesity. Circulation. 2009;120(16):1640-1645. doi:10.1161/CIRCULATIONAHA.109.192644

65. Godos J, Zappalà G, Bernardini S, Giambini I, Bes-Rastrollo M, Martinez-Gonzalez M. Adherence to the Mediterranean diet is inversely associated with metabolic syndrome occurrence: a meta-analysis of observational studies. Int J Food Sci Nutr. 2017;68(2):138-148. doi:10.1080/09637486.2016.1221900

66. Kastorini CM, Milionis HJ, Esposito K, Giugliano D, Goudevenos JA, Panagiotakos DB. The effect of Mediterranean diet on metabolic syndrome and its components: a meta-analysis of 50 studies and 534,906 individuals. J Am Coll Cardiol. 2011;57(11):1299-1313. doi:10.1016/j.jacc.2010.09.073

67. Garcia M, Bihuniak JD, Shook J, Kenny A, Kerstetter J, Huedo-Medina TB. The Effect of the Traditional Mediterranean-Style Diet on Metabolic Risk Factors: A Meta-Analysis. Nutrients. 2016;8(3):168. Published 2016 Mar 15. doi:10.3390/nu8030168

68. Esposito K, Pontillo A, Di Palo C, et al. Effect of weight loss and lifestyle changes on vascular inflammatory markers in obese women: a randomized trial. JAMA. 2003;289(14):1799-1804. doi:10.1001/jama.289.14.1799

69. Toobert DJ, Glasgow RE, Strycker LA, et al. Biologic and quality-of-life outcomes from the Mediterranean Lifestyle Program: a randomized clinical trial. Diabetes Care. 2003;26(8):2288-2293. doi:10.2337/diacare.26.8.2288

70. Jannasch F, Kröger J, Schulze MB. Dietary Patterns and Type 2 Diabetes: A Systematic Literature Review and Meta-Analysis of Prospective Studies. J Nutr. 2017;147(6):1174-1182. doi:10.3945/jn.116.242552

71. O'Connor LE, Hu EA, Steffen LM, Selvin E, Rebholz CM. Adherence to a Mediterranean-style eating pattern and risk of diabetes in a U.S. prospective cohort study. Nutr Diabetes. 2020;10(1):8. Published 2020 Mar 20. doi:10.1038/s41387-020-0113-x 
72. Esposito K, Maiorino MI, Bellastella G, Chiodini P, Panagiotakos D, Giugliano D. A journey into a Mediterranean diet and type 2 diabetes: a systematic review with meta-analyses. BMJ Open. 2015;5(8):e008222. Published 2015 Aug 10. doi:10.1136/bmjopen-2015-008222

73. Pan B, Wu Y, Yang Q, et al. The impact of major dietary patterns on glycemic control, cardiovascular risk factors, and weight loss in patients with type 2 diabetes: A network meta-analysis. J Evid Based Med. 2019;12(1):29-39. doi:10.1111/jebm.12312

74. Maiorino MI, Bellastella G, Caputo M, et al. Effects of Mediterranean diet on sexual function in people with newly diagnosed type 2 diabetes: The MÈDITA trial. J Diabetes Complications. 2016;30(8):1519-1524. doi:10.1016/j.jdiacomp.2016.08.007

75. Rizzoli R, Stevenson JC, Bauer JM, et al. The role of dietary protein and vitamin D in maintaining musculoskeletal health in postmenopausal women: a consensus statement from the European Society for Clinical and Economic Aspects of Osteoporosis and Osteoarthritis (ESCEO) [published correction appears in Maturitas. 2015 Mar;80(3):337]. Maturitas. 2014;79(1):122-132.

doi:10.1016/j.maturitas.2014.07.005

76. Cano A, Chedraui P, Goulis DG, et al. Calcium in the prevention of postmenopausal osteoporosis: EMAS clinical guide. Maturitas. 2018;107:7-12. doi:10.1016/j.maturitas.2017.10.004

77. Chevalley T, Bonjour JP, Audet MC, et al. Prepubertal Impact of Protein Intake and Physical Activity on WeightBearing Peak Bone Mass and Strength in Males. J Clin Endocrinol Metab. 2017;102(1):157-166. doi:10.1210/jc.20162449

78. Hannan MT, Tucker KL, Dawson-Hughes B, Cupples LA, Felson DT, Kiel DP. Effect of dietary protein on bone loss in elderly men and women: the Framingham Osteoporosis Study. J Bone Miner Res. 2000;15(12):2504-2512. doi:10.1359/jbmr.2000.15.12.2504

79. Haring B, Crandall CJ, Wu C, et al. Dietary Patterns and Fractures in Postmenopausal Women: Results From the Women's Health Initiative. JAMA Intern Med. 2016;176(5):645-652. doi:10.1001/jamainternmed.2016.0482

80. Craig JV, Bunn DK, Hayhoe RP, Appleyard WO, Lenaghan EA, Welch AA. Relationship between the Mediterranean dietary pattern and musculoskeletal health in children, adolescents, and adults: systematic review and evidence map. Nutr Rev. 2017;75(10):830-857.

81. Jennings A, Cashman KD, Gillings R, et al. A Mediterranean-like dietary pattern with vitamin D3 ( $10 \mu g / d)$ supplements reduced the rate of bone loss in older Europeans with osteoporosis at baseline: results of a 1-y randomized controlled trial. Am J Clin Nutr. 2018;108(3):633-640. doi:10.1093/ajcn/nqy122

82. Hannah Ritchie and Max Roser (2020) - "Mental Health". Published online at OurWorldInData.org. https://ourworldindata.org/mental-health

[Accessed 17 June 2020]

83. GBD 2016 Dementia Collaborators. Global, regional, and national burden of Alzheimer's disease and other dementias, 1990-2016: a systematic analysis for the Global Burden of Disease Study 2016. Lancet Neurol. 2019;18(1):88-106.

84. World Health Organization. Risk reduction of cognitive decline and dementia. WHO Guidelines 2019. https://www.who.int/mental health/neurology/dementia/guidelines risk reduction/en/ [Accessed 17 June 2020]

85. Singh B, Parsaik AK, Mielke MM, et al. Association of mediterranean diet with mild cognitive impairment and Alzheimer's disease: a systematic review and meta-analysis. J Alzheimers Dis. 2014;39(2):271-282. doi:10.3233/JAD130830

86. Wu L, Sun D. Adherence to Mediterranean diet and risk of developing cognitive disorders: An updated systematic review and meta-analysis of prospective cohort studies. Sci Rep. 2017;7:41317. Published 2017 Jan 23. doi:10.1038/srep41317 
87. Shannon OM, Stephan BCM, Granic A, et al. Mediterranean diet adherence and cognitive function in older UK adults: the European Prospective Investigation into Cancer and Nutrition-Norfolk (EPIC-Norfolk) Study. Am J Clin Nutr. 2019;110(4):938-948. doi:10.1093/ajen/nqz114

88. McEvoy $\mathrm{CT}$, Hoang $\mathrm{T}$, Sidney $\mathrm{S}$, et al. Dietary patterns during adulthood and cognitive performance in midlife: The CARDIA study. Neurology. 2019;92(14):e1589-e1599. doi:10.1212/WNL.0000000000007243

89. Wu J, Song X, Chen GC, et al. Dietary pattern in midlife and cognitive impairment in late life: a prospective study in Chinese adults. Am J Clin Nutr. 2019;110(4):912-920. doi:10.1093/ajcn/nqz150

90. Karstens AJ, Tussing-Humphreys L, Zhan L, et al. Associations of the Mediterranean diet with cognitive and neuroimaging phenotypes of dementia in healthy older adults. Am J Clin Nutr. 2019;109(2):361-368. doi:10.1093/ajen/nqy275

91. Samieri C, Okereke OI, E Devore E, Grodstein F. Long-term adherence to the Mediterranean diet is associated with overall cognitive status, but not cognitive decline, in women. J Nutr. 2013;143(4):493-499. doi:10.3945/jn.112.169896

92. Vercambre MN, Grodstein F, Berr C, Kang JH. Mediterranean diet and cognitive decline in women with cardiovascular disease or risk factors. J Acad Nutr Diet. 2012;112(6):816-823. doi:10.1016/j.jand.2012.02.023

93. Marshall S, van der Meij B. Fish and omega-3 intake and health in older people. Maturitas. 2018;115:117-118. doi:10.1016/j.maturitas.2018.04.002

94. Malhi GS, Outhred T, Hamilton A, et al. Royal Australian and New Zealand College of Psychiatrists clinical practice guidelines for mood disorders: major depression summary. Med J Aust. 2018;208(4):175-180.

95. Molendijk M, Molero P, Ortuño Sánchez-Pedreño F, Van der Does W, Angel Martínez-González M. Diet quality and depression risk: A systematic review and dose-response meta-analysis of prospective studies. J Affect Disord. 2018;226:346-354. doi:10.1016/j.jad.2017.09.022

96. Lassale C, Batty GD, Baghdadli A, et al. Healthy dietary indices and risk of depressive outcomes: a systematic review and meta-analysis of observational studies [published correction appears in Mol Psychiatry. 2018 Nov 21;:]. Mol Psychiatry. 2019;24(7):965-986. doi:10.1038/s41380-018-0237-8

97. Shafiei F, Salari-Moghaddam A, Larijani B, Esmaillzadeh A. Adherence to the Mediterranean diet and risk of depression: a systematic review and updated meta-analysis of observational studies [published correction appears in Nutr Rev. 2019 Jun 1;77(6):454]. Nutr Rev. 2019;77(4):230-239. doi:10.1093/nutrit/nuy070

98. Elstgeest LEM, Winkens LHH, Penninx BWJH, Brouwer IA, Visser M. Associations of depressive symptoms and history with three a priori diet quality indices in middle-aged and older adults. J Affect Disord. 2019;249:394-403. doi:10.1016/j.jad.2019.02.004

99. Gibson-Smith D, Bot M, Brouwer IA, Visser M, Giltay EJ, Penninx BWJH. Association of food groups with depression and anxiety disorders. Eur J Nutr. 2020;59(2):767-778. doi:10.1007/s00394-019-01943-4

100. Masana MF, Haro JM, Mariolis A, et al. Mediterranean diet and depression among older individuals: The multinational MEDIS study. Exp Gerontol. 2018;110:67-72. doi:10.1016/j.exger.2018.05.012

101. Recchia D, Baghdadli A, Lassale $C$, et al. Associations between long-term adherence to healthy diet and recurrent depressive symptoms in Whitehall II Study. Eur J Nutr. 2020;59(3):1031-1041. doi:10.1007/s00394-01901964-z

102. Fresán U, Bes-Rastrollo M, Segovia-Siapco G, et al. Does the MIND diet decrease depression risk? A comparison with Mediterranean diet in the SUN cohort. Eur J Nutr. 2019;58(3):1271-1282. doi:10.1007/s00394-018-1653-x

103. Gangwisch JE, Hale L, Garcia L, et al. High glycemic index diet as a risk factor for depression: analyses from the Women's Health Initiative. Am J Clin Nutr. 2015;102(2):454-463. doi:10.3945/ajen.114.103846

104. Jacka FN, O'Neil A, Opie R, et al. A randomised controlled trial of dietary improvement for adults with major depression (the 'SMILES' trial) [published correction appears in BMC Med. 2018 Dec 28;16(1):236]. BMC Med. 2017;15(1):23. Published 2017 Jan 30. doi:10.1186/s12916-017-0791-y 
105. Schwingshackl L, Hoffmann G. Adherence to Mediterranean diet and risk of cancer: a systematic review and meta-analysis of observational studies. Int J Cancer. 2014;135(8):1884-1897. doi:10.1002/ijc.28824

106. Buckland G, Travier N, Cottet V, et al. Adherence to the mediterranean diet and risk of breast cancer in the European prospective investigation into cancer and nutrition cohort study. Int J Cancer. 2013;132(12):2918-2927. doi:10.1002/ijc.27958

107. Couto E, Sandin S, Löf M, Ursin G, Adami HO, Weiderpass E. Mediterranean dietary pattern and risk of breast cancer. PLoS One. 2013;8(2):e55374. doi:10.1371/journal.pone.0055374

108. Castelló A, Pollán M, Buijsse B, et al. Spanish Mediterranean diet and other dietary patterns and breast cancer risk: case-control EpiGEICAM study. Br J Cancer. 2014;111(7):1454-1462. doi:10.1038/bjc.2014.434

109. Toledo E, Salas-Salvadó J, Donat-Vargas C, et al. Mediterranean Diet and Invasive Breast Cancer Risk Among Women at High Cardiovascular Risk in the PREDIMED Trial: A Randomized Clinical Trial [published correction appears in JAMA Intern Med. 2018 Dec 1;178(12):1731-1732]. JAMA Intern Med. 2015;175(11):1752-1760. doi:10.1001/jamainternmed.2015.4838

110. Chlebowski RT, Aragaki AK, Anderson GL, et al. Dietary Modification and Breast Cancer Mortality: Long-Term Follow-Up of the Women's Health Initiative Randomized Trial. J Clin Oncol. 2020;38(13):1419-1428. doi:10.1200/JCO.19.00435

111. Martínez-González MA, Salas-Salvadó J, Estruch R, et al. Benefits of the Mediterranean Diet: Insights From the PREDIMED Study. Prog Cardiovasc Dis. 2015;58(1):50-60. doi:10.1016/j.pcad.2015.04.003 